\title{
O USO PÚBLICO PARA INSERÇÃO SOCIAL E CONSCIENTIZAÇÃO QUANTO AO PATRIMÔNIO NATURAL EM NOVA IGUAÇU/RJ
}

\author{
MARCOS PAULO MORAES OLIVEIRA ${ }^{1}$ \\ ISABELA DE FÁTIMA FOGAÇA ${ }^{2}$
}

DOI: https://doi.org/10.47977/2318-2148.2020.v8n13p1

\begin{abstract}
RESUMO
O espaço geográfico que conhecemos por Baixada Fluminense, integra a região metropolitana do estado do Rio de Janeiro e, como todo o país, dispõe de uma diversidade cultural, desde sua origem. Entretanto, o cenário real conta com muita insalubridade, violência e extrema pobreza, principalmente nas áreas mais afastadas e/ou rurais, o que causa certa insatisfação por parte de seus habitantes os quais, em sua maioria, não colocam as questões ambientais como prioridade. Na intenção de promover a integração do uso público com o patrimônio natural com base em revisão bibliográfica, é debatida a interação e a participação social sob uma perspectiva da educação ambiental em áreas protegidas dentro do cenário geográfico selecionado. Foi apresentado um breve histórico sobre a região e os espaços de proteção ambiental existentes, descrevendo-se possíveis medidas que permitam integrar pessoas e meio ambiente em seus espaços de vivência. Neste sentido, foram apresentados e descritos os projetos educativos: 'Aprendendo e Preservando', 'Limpando para Proteger' e 'Operação Tolerância Zero', já disponibilizados junto à prefeitura de Nova Iguaçu.
\end{abstract}

Palavras-Chave: Baixada fluminense; meio ambiente; relação homem e natureza.

\section{PUBLIC USE FOR SOCIAL INSERTION AND AWARENESS REGARDING NATURAL HERITAGE IN NOVA IGUAÇU / RJ - BRAZIL}

\begin{abstract}
The geographical space known as Baixada Fluminense integrates the metropolitan region of the state of Rio de Janeiro and, like the whole country, has a cultural diversity, since its origin. However, the real scenario has a lot of unhealthiness, violence and extreme poverty, especially in the most remote and / or rural areas, which causes some dissatisfaction on the part of its inhabitants who, in their majority, do not place environmental issues as a priority. With the intention of promoting the integration of public use with natural heritage based on a bibliographic review, interaction and social participation are discussed from the perspective of environmental education in protected areas within the selected geographical scenario. A brief history of the region and the existing environmental protection spaces was presented, describing possible measures that allow people and the environment to be integrated into their living spaces. In this sense, the educational projects were presented and described: 'Learning and Preserving', 'Cleaning to Protect' and 'Operation Zero Tolerance', already available from the Nova Iguaçu City Hall.
\end{abstract}

Key Words: Baixada fluminense, environment, men and nature relationship.

\footnotetext{
${ }^{1}$ Mestrando pelo Programa de Pós-Graduaçãoem Patrimônio, Cultura e Sociedade da Universidade Federal Rural do Rio de Janeiro (PPGPACS/UFRRJ). E-mail: mpoliveiraufrrj@gmail.com

${ }^{2}$ Departamento de Administração e Turismo (DAT/UFRRJ); Professora do Programa de Pós-Graduação em Patrimônio, Cultura e Sociedade da Universidade Federal Rural do Rio de Janeiro (PPGPACS/UFRRJ). Email: isafog@hotmail.com
} 


\section{INTRODUÇÃO}

A apropriação do natural como patrimônio cultural no Brasil é um dos grandes desafios da educação contemporânea e da corresponsabilidade social na gestão de áreas naturais nas cidades brasileiras.

Em áreas periféricas, como no caso das cidades da Baixada Fluminense (Região Metropolitana do Estado do Rio de Janeiro - RMRJ), sob forte carência de políticas educacionais e de estruturas que proporcionem qualidade de vida e autoestima, existem grandes oportunidades comerciais, agrícolas e, também, na área turística. Muitos moradores locais desconhecem estas potencialidades, havendo a necessidade de acesso às informações e, consequentemente, estímulo ao interesse e participação.

Se os temas ambientais forem pontes alternativas para reafirmar a identidade e estabelecer uma afetividade do sujeito com o seu habitat, é possível que a ideia de ressignificar a história deste grupo social vulnerável possa cooperar e valorizar esta correlação. O emprego da abordagem da conservação e/ou preservação, considerando o tema do uso público nas áreas naturais como uma questão permanentemente levantada, não apenas sob a ótica da beleza cênica do espaço, mas também por se relacionar com a qualidade de vida que possa ser ofertada.

Nesse sentido, ao discutir a apropriação cultural dos recursos naturais e a salvaguarda desse patrimônio em áreas protegidas como as estudadas nesta pesquisa, julgamos ser necessário trazer um breve histórico sobre este espaço geográfico; analisar os atrativos e sua importância para conservação; e apresentar uma ou mais alternativas de envolvimento e participação social.

Se é preciso valorizar as práticas sociais, medidas precisam ser tomadas para que a Baixada Fluminense possa imprimir uma nova verdade, por intermédio de um bem de interesse comum: fazer do uso público uma ferramenta na conscientização do meio ambiente.

\section{MÉTODO DE ESTUDO}

Esta pesquisa adotou uma análise qualitativa-descritiva, com base em levantamento e interpretação bibliográfica. Foi utilizado o conceito de 'patrimônio cultural natural' e o de 'uso público', abordando outras pesquisas teóricas e/ou empíricas que associam soluções que demandem interação e que reforcem a interdependência de ambos. As unidades de estudo comportam muito mais do que ambientes recreativos e/ou turísticos, mas que também dispõem de tamanha relevância para a conservação e preservação do meio ambiente. É primordial destacar que a compreensão social sobre as ações de conservação do meio ambiente, possibilita melhoria geral das condições de vida. Entretanto, assinalamos que este estudo é apenas uma parte inicial de uma pesquisa em andamento sobre o tema patrimônio cultural natural na Baixada Fluminense.

\section{NOVA IGUAÇU E A BAIXADA FLUMINENSE}

Localizada na Região Metropolitana do Rio de Janeiro (RMRJ), a Baixada Fluminense é uma microrregião que surge a partir do ano de 1826 iniciando-se pela grande Iguaçu e que hoje é desmembrada em treze municípios independentes. Seu crescimento se deu pela expansão da linha férrea e da migração dos mais pobres e mais diversos por questões econômicas (SANTANA et al, 2013),

De acordo com Senra e Andrade (2017), a Baixada Fluminense, desde então, conformou-se por municípios, visualmente, insalubres que, dependendo da região, assumem características entre rural e urbano. Desde as décadas de 1970 e 1980, a imprensa costuma divulgar, com frequência, uma imagem de violência, baseada em corrupção e na ação de milícias. 
É importante destacar que grandes empreendimentos industriais se instalaram na região, elevando a Baixada a um importante patamar econômico. Todavia, isso não resultou em desenvolvimento socioespacial, com reflexos nos problemas associados à 'pobreza, precariedade dos serviços urbanos, clientelismo e personalismo político e, talvez aquela que seja a imagem mais difundida, a violência' (SENRA e ANDRADE, 2017, p. 266). Os efeitos negativos sobre sua população trazem, para os cidadãos residentes, a negação de vínculos e de sentimentos de pertencimento com os seus próprios locais de moradia.

Nova Iguaçu se configurou como um dos núcleos centrais, junto a Duque de Caxias, no complexo regional da Baixada Fluminense, seja por sua extensão territorial, população ou comércio. Furlanetto et al (1987, p 34) afirmam que Nova Iguaçu, mesmo após a fragmentação de seu território, continuou sendo 'o único entre todos os da periferia que apresenta maior tendência de autonomia de funções em relação ao município do Rio de Janeiro'. Nova Iguaçu é a cidade mais antiga da Baixada, criada em 1833, na época denominada de Vila de Iguassú e tinha o mesmo nome do rio que por ela cruzava. Ali também passava a Estrada Real do Comércio, pela qual era escoada a produção de cana-deaçúcar e do café das áreas serranas de seu entorno.

De acordo com Pereira (1977), no século XX, ali se desenvolveu, como atividade central, o plantio de laranjas, o que revolucionou a estrutura socioeconômica local. Seus pomares se estendiam por diversos bairros, seu cheiro era tão forte e agradável que a cidade era conhecida como 'Cidade Perfume', fazendo com que a agricultura já fosse um assunto importante desde os primeiros relatos históricos locais.

Na contemporaneidade, o município de Nova Iguaçu dispõe de um importante centro comercial para o estado do Rio de Janeiro e uma variedade de recursos, incluindo a fauna e flora, rios e cachoeiras, áreas de lazer, polos de moda e de comércio, agricultura, festas tradicionais e religiosas, centros de cultura, entre outros (PREFEITURA MUNICIPAL DE NOVA IGUAÇU, s.d.). Além disso, existem novas possibilidades de desenvolvimento socioeconômico, envolvendo atividades, como, por exemplo, o turismo. No entanto, são inúmeros os desafios para se alcançar esse patamar, entre eles está a valorização e gestão sustentável de suas áreas naturais por parte de seus governantes. Destaca-se, no caso de sua população, a frágil autoestima diante da pouca visibilidade, interação social e o próprio interesse dos indivíduos em querer integrar-se no desenvolvimento sustentável de seu habitat natural.

Um dos fatores mais relevantes de destaque sobre Nova Iguaçu são os seus atrativos ecológicos, visto que $69 \%$ do território iguaçuano é composto por áreas de proteção integral ou de uso sustentável, vide Queiroz (2018, p. 72). Todavia, esses espaços são pouco conhecidos e explorados por seus moradores e vizinhos, logo, pouco valorizados.

Nesse sentido, destaca-se a emergência da discussão de temas sobre conservação e do reconhecimento dos recursos naturais, presentes no município, como patrimônio cultural natural das comunidades de seu entorno, até mesmo no intuito de estimular a inserção social desta comunidade tão prejudicada devido às carências presentes em sua realidade.

Meneses et al (2006, p. 39) nos diz que 'o principal sujeito da cultura é o habitante local'. Porém, caso os cidadãos consigam perceber-se como principais responsáveis na conservação do meio onde vive, haveriam efeitos preventivos e positivos para a própria Baixada Fluminense. Na falta de interesse e/ou de informação, o meio ambiente continua a ser uma das principais preocupações que tendem ao abandono e ao descaso, mesmo que inconscientemente saibamos que homem e natureza se complementam.

\section{HOMEM E NATUREZA: UMA INTERAÇÃO NECESSÁRIA}

A orientação dos indivíduos em seu espaço depende da adoção de práticas convencionais condizentes com a sua vinculação social. É indiscutível pensar que as 
relações sociais poderiam assumir um papel independente. Cuche (2002) nos diz que as culturas nascem das próprias relações sociais e não são iguais, necessariamente. Por isso, pensar no meio ambiente nos garante acesso a um homem que queira se predispor a cuidar do seu habitat e colocar as necessidades dos seus em primeiro lugar.

Conforme os estudos avançam, a relação homem e natureza configura um cenário promissor. No cenário atual, a ação cultural junto ao meio ambiente vem se manifestando e se modulando na direção da sustentabilidade, ao contrário do que se observou no passado, onde não se permitia uma interação preservacionista (SCIFONI, 2008).

Segundo Santos (2002), o bem de valor natural depende de uma participação híbrida entre o físico e o social, na qual o sujeito vivifica substancialmente o meio, em que o valor a ser atribuído a este depende de encontrarmos nele significado. Nesse sentido, a paisagem torna-se indispensável na significação e ressignificação do sujeito, ainda que para o homem seja difícil distinguir o valor social do natural. Separados (homem e natureza) são encontrados como verdades parciais e suas existências dependem das relações sociais que assim as determinam, não só como de importância material em objeto, mas também como valor social, cultural e natural.

É preciso compreender que 'a paisagem é o conjunto de forma que, num dado momento, exprimem as heranças que representam as sucessivas relações localizadas entre homem e natureza' (SANTOS, 2002, p. 66), o que afere a dependência do bem natural ao seu valor social sabendo que homem e espaço o compõem. A sua conservação deva partir do interesse dos seus e, por estarmos falando de um patrimônio que também é composto por áreas protegidas, um dos grandes problemas enfrentados pelos gestores das Unidades de Conservação (UC), é o distanciamento da população em relação aos objetivos de conservação (BRITO, 2007). Neste contexto, mais do que nunca, são fundamentais os processos de comunicação para se chegar à população, motivá-la, aproximá-la e implicá-la na estratégia de conservação de uma área já protegida, ou que possa vir a ser.

Infelizmente, por inúmeras razões, as áreas periféricas tendem a fazer com que o morador ressinta a se identificar como parte integrante do seu habitat cultural e natural, e medidas como estímulo a uma identificação, preservação e conservação se tornem cada vez mais desafiadores e complexos, porém não impossíveis de serem questionados, estudados e aplicados, se pensadas em coerência as diretrizes de uso público em unidades de conservação.

Seguindo o princípio de Pelegrini (2006, p. 127) de que 'à medida que o cidadão se percebe como parte integrante de seu entorno, tende a elevar sua autoestima e a valorizar sua identidade cultural', mais uma vez, pensar na interação homem e natureza é uma das formas de não só valorizar uma identidade cultural, mas o de pensarmos que esta interação gera frutos de sustentabilidade, conservação e preservação e possibilitar-se-á que gerações futuras possam entender que é preciso cuidar mais do seu habitat natural, primando-se a 'diversidade cultural e pela união entre o homem e a natureza de modo a garantir a gestão democrática dos espaços territoriais e o adequado manejo das áreas de proteção ambiental' (PELEGRINI, 2006, p. 118).

Em sequência, os estudos de Maximiano (2002) evidenciam que o bem natural assegura, também, uma configuração de memória coletiva e de herança ou patrimônio cultural, seja pelo valor paisagístico, seja pelo contexto que representa para com a sociedade na sua interação com o mundo em sua volta, o meio ambiente.

$\mathrm{E}$, por mais que as diferentes ciências tendem a unilaterizar o patrimonio cultural como se ele fosse um bem de posse ou físico, hoje as leis e a Constituição nos permitem explorar um lado do patrimônio, que demanda a interação social e que leva questões como o meio ambiente como prioridade, abrangendo o que hoje conhecemos por patrimônio cultural natural. 


\title{
O PATRIMÔNIO CULTURAL NATURAL
}

No Brasil, a Constituição Federal de 1988 ampliou da noção do conceito de Patrimônio Cultural a partir de seu Artigo 216. Neste artigo, definem-se os bens que compõem o patrimônio cultural brasileiro, trazendo à tona a perspectiva material e imaterial do bem cultural. Somam-se a estes bens os valores ecológicos configurados também como patrimônios culturais da nação (BRASIL. Constituição Federal de 1988. Seção II, Artigo 216).

Ainda na antiga Constituição Federal Brasileira, de 1937 (BRASIL, 1937, s.p), em seu artigo 134, era destacado que 'os monumentos históricos, artísticos e naturais, assim como as paisagens ou os locais particularmente dotados pela natureza' deveriam gozar “... da proteção e dos cuidados especiais da Nação, dos Estados e dos Municípios".

No âmbito mundial, em 1972 (Paris), na Convenção sobre a Proteção do Patrimônio Mundial, Cultural e Natural aprovada pela Conferência Geral, da Organização das Nações Unidas para a Educação, a Ciência e a Cultura (UNESCO), discutiu-se, a conjugação do 'natural' como patrimônio cultural e, a partir deste encontro, o patrimônio cultural natural passa a ser definido como:

\begin{abstract}
Os monumentos naturais constituídos por formações físicas e biológicas ou por grupos de tais formações, que tenham valor universal excepcional do ponto de vista estético ou científico; As formações geológicas e fisiográficas e as áreas nitidamente delimitadas que constituam o habitat de espécies animais e vegetais ameaçadas e que tenham valor universal excepcional do ponto de vista estético ou científico; Os lugares notáveis naturais ou as zonas naturais estritamente delimitadas, que tenham valor universal excepcional do ponto de vista da ciência, da conservação ou da beleza natural (UNESCO, 1972, p.2).
\end{abstract}

No estado do Rio de Janeiro, o patrimônio natural é um assunto ainda pouco explorado, visto que raras foram às declarações para estes bens no âmbito do órgão responsável pela salvaguarda do patrimônio cultural no estado, o Instituto Estadual de Patrimônio Cultural (INEPAC). Ali estão protegidos como patrimônio cultural natural a Serra do Mar, cobertura florestal tropical tombada provisoriamente desde 1991, que perpassa 38 municípios do estado, e o Reservatório de Rio d'Ouro, no município de Nova Iguaçu, tombado em 1989 (INEPAC, 2020).

Pereira $(2018$, p.47) destaca que entre os valores motivadores do tombamento de tais áreas, 'observou-se um predomínio do cênico-paisagístico, seguido pelo valor histórico, somando 69\% dos valores atribuídos na identificação do patrimônio natural'. Em 2019, houve o tombamento do rio Carioca como patrimônio cultural pelo INEPAC ${ }^{3}$, o primeiro curso d'água urbano tombado no país. Neste tombamento, pode-se perceber a ação social como motivação para a declaração. De acordo com reportagem de O Globo (janeiro de 2019), um dos relatos é de que antes não se tinha ideia do que o rio representava, mas com o tombamento, a percepção da comunidade mudou drasticamente.

Assim, percebe-se que ainda há muito que se avançar na compreensão do natural como um patrimônio diretamente relacionado ao modo de vida e de reprodução da sociedade. Os processos de declaração como patrimônio cultural natural ou os processos de tombamento destas áreas, seja em âmbito federal, estadual ou municipal, relacionaram-se até o momento à grandiosidade do monumento natural e não ao seu valor social às comunidades de seu entorno.

\footnotetext{
${ }^{3}$ Reconhecido como o primeiro curso d'água a abastecer a cidade com água potável, ainda no Brasil Colônia. "O simbolismo do Rio Carioca como patrimônio da cidade vai além da herança do gentílico. Inicialmente fonte de recursos dos índios Tamoios, ele motivou a construção dos Arcos da Lapa, caminho para encher os chafarizes da cidade, incluindo o Chafariz da Carioca, hoje Largo, entre 1700 e 1800" (O GLOBO, 2019).
} 
Da mesma forma, o reconhecimento destas áreas como patrimônio natural, é instrumento imprescindível para proteger uma unidade de conservação, ou outro ambiente natural, dos impactos que os visitantes e demais usuários (não moradores do entorno) podem ocasionar.

\section{ANÁLISE DO CENÁRIO}

Como descrito por Queiroz (2018, p. 72), 69\% do território iguaçuano é composto por áreas de proteção integral ou de uso sustentável, onde abriga oito áreas de proteção ambiental (APAs) municipais, um Parque Natural Municipal (PNMNI), duas APAs estaduais (Rio Guandu e Mendanha-Gericinó), um Parque Estadual (Parque Estadual do Mendanha) e a Reserva Biológica de Tinguá (federal).

Conforme Silva e Souza (2017, p.1) a Reserva Biológica do Tinguá (REBIO Tinguá) é 'a maior reserva biológica da Mata Atlântica existente no Estado do Rio de Janeiro.' Criada em 1989, conserva em seu território - cerca de 26 mil hectares e 150 quilômetros de perímetro, aproximadamente, $0,6 \%$ do estado -, importantes trechos de biodiversidade, que correspondem a $8 \%$ das florestas protegidas do estado e mananciais de águas de excelente qualidade, importantes para o abastecimento de parte do estado do Rio de Janeiro (TCE/RJ, 2008). Abrange parte dos municípios de Nova Iguaçu, Duque de Caxias, Petrópolis, Miguel Pereira e Vassouras - mas sua entrada principal se dá pelo município de Nova de Iguaçu.

De acordo com o Tribunal de Contas do Estado do Rio de Janeiro (TCE/RJ, 2008, p.12), a REBIO Tinguá 'possui relevo acidentado, com escarpas sulcadas por rios torrenciais, onde destaca-se o maciço do Tinguá, com 1.600m de altura'. E, além da riqueza em biodiversidade, representada em sua fauna e flora, foi composta por fazendas do período colonial, o que resulta em um remanescente de patrimônio histórico edificado, como a estrada do comércio, entre outros, infelizmente, parte em ruínas.

O Parque Natural Municipal de Nova Iguaçu (PNMNI), por sua vez, criado em 1998, pelo Decreto Municipal 6001, está localizado entre os municípios Nova Iguaçu e Mesquita. O PNMNI ocupa uma área de 1100 hectares e foi idealizado a partir da preocupação de se preservar a fauna e a flora ali presente, diferente da REBIO Tinguá cujo acesso é restrito. $\mathrm{O}$ parque surge como uma alternativa de lazer para a comunidade local e vizinha, além de representar grande valor para a biodiversidade, de grande interesse geológico por contar com um vulcão adormecido há mais de quarenta milhões de anos, o que, em 2005, resultou à unidade de conservação o recebimento do título de geoparque.

De acordo com a Secretaria Municipal de Meio Ambiente e Urbanismo (SEMUAM, 2001), o PNMNI dispõe de, aproximadamente, quatorze poços e cachoeiras para recreação e lazer, trilhas ecológicas, locais para rapel, voos de asa delta e apelo histórico-cultural. Entre os patrimônios históricos ali catalogados estão a Fazenda Dona Eugênia - o casarão, como é popularmente conhecido, construído nos finais do século XIX; as ruínas do clube Dom Felipe; e o Quilombo. Entre as trilhas e locais de visitação mais conhecidas estão o Caminho das Águas; Caminho Geológico I e II; o Casarão; as Ruínas do Clube D Felipe; e, a Trilha da Varginha. Ainda há a antiga pedreira São José e Mirante da Pedreira; o Vulcão; a Cachoeira Véu de Noiva; o Poço das Cobras; e a Represa Epaminondas Ramos localizada nas proximidades do principal acesso de entrada ao parque que se dá pelo município de Mesquita. Ressaltamos que o PNMNI hoje é a unidade de conservação mais visitada na Baixada Fluminense.

O Parque Estadual do Mendanha se localiza entre os municípios de Mesquita, Nova Iguaçu e Rio de Janeiro, e possui uma área de 4.398,10 hectares (INEA, 2020). A área também tem como proposta a prática de atividades de lazer ao ar livre que não perturbem o ambiente natural e/ou prejudiquem os animais. O parque é frequentado pela população do 
entorno e de municípios vizinhos e visitado por um pequeno fluxo de turistas que procuram o parque para atividades de lazer.

Existem ainda as Áreas de Proteção Ambiental (APAs) de Nova Iguaçu. Contudo, apenas três delas possuem planos de manejo: Jaceruba, Tinguá e Rio D’Ouro. Boa parte da população desconhece a existência e localização destas unidades, tampouco sua funcionalidade e a importância para uma melhor qualidade de suas vidas e de importantes espécies animais (QUEIROZ, 2018).

\section{A SITUAÇÃO JUNTO A COMUNIDADE E MEDIDAS A SEREM TOMADAS}

Infelizmente, a gestão destas áreas de conservação ambiental enfrentam problemas em relação à visitação e na relação com os moradores do entorno. Ocorrem muitos impactos negativos gerados pela depredação, desvalorização, acesso, caça e pesca ilegais, poluição, violência e outros fatores críticos. São atributos que desassociem a imagem de cuidado e zelo que deveríamos prezar se estamos falando de uso público em unidades de conservação.

Para melhor visualizar, exemplificamos uma pesquisa realizada junto aos moradores do município de Nova Iguaçu, no bairro Tinguá, área de entorno imediato da UC REBIO Tinguá. Oliveira e Rodrigues (2013, p. 37) assinalaram que a maior parcela dos residentes entrevistados e moradores nas proximidades da reserva, não tinham conhecimento da sua existência. Dos entrevistados, $66 \%$ declararam que já visitaram a reserva e dentre eles, $22 \%$ praticam atividades físicas no local ou arredores, $14 \%$ usam para banho nas cachoeiras e somente $2 \%$ alegaram ter ido para fins educativos. Os mesmos autores (2013, p.38) destacaram também que 'durante as entrevistas muitos moradores e comerciantes reclamaram que a destruição das barragens, que formavam piscinas de águas naturais, prejudicou a renda que a localidade ganhava com os visitantes' o que evidencia os conflitos existentes entre os sítios de entorno da UC com as normas para sua gestão.

Por outro lado, a referida pesquisa trouxe um dado que consideramos positivo, ou seja, o papel da sociedade nos cuidados com a área. Ao questionar os entrevistados sobre quem deve cuidar da reserva $34 \%$ indicou o ICMBio e $33 \%$ a sociedade, e $7 \%$ apontou uma parceria entre ICMBio e sociedade, o que demonstra a noção da responsabilidade social com aquele bem.

A Baixada Fluminense apresenta um retrato contemporâneo das discrepâncias socioculturais que existem em nosso país. Uma relação, extremamente dialética, que podemos exemplificar a partir da comunidade que vive no bairro Coréia, em Mesquita, na entrada principal do PNMNI, que sofre com problemáticas de segurança pública, mas que demonstra afeição para com aquele patrimônio natural que representa seu habitat, seu espaço de produção e de reprodução de sua vida cotidiana.

Em contrapartida a esse emaranhado de problemas, queremos destacar iniciativas positivas na forma de alguns projetos de conscientização e preservação ambiental já em desenvolvimento. Um deles é o projeto "Aprendendo e Preservando", realizado no PNMNI, cujo principal objetivo é desenvolver o sentimento de pertencimento guiando-se pela necessidade do indivíduo preservar aquilo que ele conhece (QUEIROZ, 2018, p. 113). Todavia, Queiroz (2018) pondera que, por falta de funcionários, o projeto é apenas realizado com as escolas da rede municipal de Nova Iguaçu, não atingindo ao público-alvo de entorno que não esteja vinculado ao grupo escolar.

Outra iniciativa citada por Queiroz (2018, p. 113-114) é o projeto "Limpando para Proteger". Segundo a autora, nesse projeto a guarda ambiental realiza abordagens ao observar as ações dos visitantes que condizem, ou não, com a conservação do espaço e que possam sensibilizar o usuário. Além disso, conta com mutirões de limpeza, também com o intuito de sensibilizar visitantes. Em períodos de alta demanda, como no verão, o trabalho é 
feito com uma maior intensidade, visto a grande movimentação na UC. Há ainda, projeto o “Operação Tolerância Zero", cuja função é fiscalizar e proibir a caça e o desmatamento. E caso ocorra infração, realizar-se-á a devida punição por multa ou até prisão.

\section{CONSIDERAÇÕES FINAIS}

Os estudos realizados por Queiroz (2018), Pereira (2018), Oliveira e Rodrigues (2013) demonstraram que há interesse pelas áreas naturais por parte das comunidades, mas que também ainda existe certo distanciamento em relação à gestão das UC. São valorosas as iniciativas de trabalho que vêm sendo feitas junto às escolas da região com projetos de visitação, principalmente nos casos do PNMNI e REBIO Tinguá, onde educadores trabalham com seus alunos temas voltados para a educação ambiental. Não é conveniente esperar somente as iniciativas do poder público, pois os danos podem ser irreversíveis. É essencial trabalhar pela ampliação da participação social mais abrangente para conservação dos sítios.

Sabemos que o patrimônio natural não representa apenas os testemunhos de uma vegetação nativa, intocada, ou ecossistemas pouco transformados pela sociedade. Ele por sua vez, também, como diz Scifoni (2008, p.16) 'faz parte da memória social, ele incorpora, sobretudo, paisagens que são objeto de uma ação cultural pela qual a vida humana se produz e reproduz.' Por isso, não só por compreender uma paisagem, a fauna e/ou a flora, mas também é preciso fazer com que o homem veja o meio ambiente como elemento central de suas vidas, pois não temos o hábito de nos preocuparmos com o nosso habitat, com a sustentabilidade, e com sua conservação, o que só nos garantem perdas. Não queremos que casos recorrentes como os que vemos acontecer na Floresta Amazônica, apresentados diariamente pela mídia, sejam exemplos para as nossas cidades. Temos provas vivas de que a Baixada é verde, seu espaço é do povo. Mas, se o ignorarmos e depredá-lo, o mal só está sendo feito por nós e para nós mesmos. Se a conscientização é um viés de intervenção social, precisamos focar nela não só por explorar a relação homem e natureza, mas principalmente por termos a consciência de que somos tão dependentes dela quanto ela é de nós.

Enfim, faz-se necessário dizer que, esta pesquisa não termina apenas com esta análise até porque, a Baixada Fluminense já é depreciada pelo senso comum, se não buscarmos e viabilizarmos através de pesquisas científicas, formas de reverter esse cenário, o senso comum continuará a reproduzir este dilema, visto que ainda não há o suporte necessário nem nas escolas para com a educação ambiental, patrimonial e o principal para com a história que compõe esse conglomerado geográfico. Sendo assim, como exigir do homem que ele intervenha em favor do natural se ele nem ao menos o conhece? 


\section{REFERÊNCIAS BIBLIOGRÁFICAS}

BRASIL. Constituição da República Federativa do Brasil. Diário Oficial da União, Rio de Janeiro, DF, 1937.

BRASIL. Constituição da República Federativa do Brasil. Diário Oficial da União, Brasília, DF, 1988.

BRITO, Francisco Emanuel Matos. Ecos contraditórios do turismo. Salvador: Edufba, 2007. 197p

CUCHE, Denys. A noção de cultura nas ciências sociais. 2a Ed. Bauru: EDUSC, 2002.

FURLANETTO, Diva Almeida; CRUZ, Jana Maria; ALMEIDA, Roberto Schmidt. Promoção Imobiliária e espaço residencial da classe média na periferia metropolitana do Rio de Janeiro. Revista Brasileira de Geografia, Rio de Janeiro, v.49, n.2, p. 27-56, abr./jun. 1987.

INEA. Instituto Estadual do Ambiente. Parque Estadual do Mendanha. Disponível em: <http://www.inea.rj.gov.br/biodiversidade-territorio/conheca-as-unidades-deconservacao/parque-estadual-do-mendanha/>. Acesso em: 10 de maio de 2020.

INEPAC. Instituto Estadual do Patrimônio Cultural. Patrimônio Cultural Bens Tombados. Disponível em: < http://www.inepac.rj.gov.br/index.php/bens tombados/realizabusca?municipios=50\&Bem Cultural $=\&$ PalavraChave $=>$. Acesso em: Maio de 2020.

MAXIMIANO, Liz Abad. Classificação de paisagens no norte de Campo Largo Paraná, segundo sua condição socioambiental. Dissertação (Mestrado) - Universidade Federal do Paraná, Curitiba, 2002.

MENESES, Ulpiano Toledo Bezerra de; ARANTES NETO, Antonio Augusto; CARVALHO, Edgard de Assis; MAGNANI, José Guilherme Cantor; AZEVEDO, Paulo Ormindo David de. A cidade como bem cultural: áreas envoltórias e outros dilemas, equívocos e alcance da preservação do patrimônio ambiental urbano. [Debate].

Patrimônio : atualizando o debate[S.l: s.n.], 2006.

O GLOBO. Rio Carioca se torna primeiro curso d'água urbano do país a virar patrimônio cultural. 11 de janeiro de 2019. Disponível em: <

https://oglobo.globo.com/rio/bairros/rio-carioca-se-torna-primeiro-curso-dagua-urbano-dopais-virar-patrimonio-cultural-23362284 >. Acesso em junho de 2020.

OLIVEIRA, Andréia S. Lopes S.; RODRIGUES, Camila Gonçalves Oliveira.

Mapeamento e análise do uso público e da percepção ambiental das comunidades da área de abrangência da Reserva Biológica do Tinguá, 87f. 2013. Relatório (Iniciação Científica). Universidade Federal Rural do Rio de Janeiro, Nova Iguaçu, 2013.

PELEGRINI, Sandra. C. A. Cultura e natureza: os desafios das práticas preservacionistas na esfera do patrimônio cultural e ambiental. Revista Brasileira de História (Impresso), São Paulo, v. 26, n.51, p. 115-140, 2006.

PEREIRA, D. C. Patrimônio natural: atualizando o debate sobre identificação e reconhecimento no âmbito do Iphan. Revista CPC, [S. l.], v. 13, n. 25, p. 34-59, 2018. DOI: 10.11606/issn.1980-4466.v13i25p34-59. Disponível em: < http://www.revistas.usp.br/cpc/article/view/138007> . Acesso em: 5 de maio de 2020.

PEREIRA, Waldik. Cana, Café e Laranja: história econômica de Nova Iguaçu. Rio de Janeiro. Fundação Getúlio Vargas: SEEC, 1977.170p.

PREFEITURA DA CIDADE DE NOVA IGUAÇU - Parque Natural Municipal de Nova Iguaçu. Disponível em: < https://www.novaiguacu.rj.gov.br/semadetur/parque-naturalmunicipal-de-nova-iguacu/ >. Acesso em: 10 de junho de 2020. 
QUEIROZ, Edileuza. D. Uso Público no Parque Natural Municipal de Nova Iguaçu RJ: Trilhando entre possibilidades e dificuldades. 2018. 190f. Tese (Doutorado em Geografia) - Universidade Federal Fluminense. Niterói, Rio de Janeiro, 2018.

SANTANA, T. G. ; SILVA, N. C. R. ; MAGALHAES, S. P. ; MOREIRA, E. ; SANTOS, D. N. ; CARDOSO, Cristiane . (Re)descobrindo a Baixada Fluminense: A transformação do olhar do discente sobre os problemas socioambientais. In: XIV EGAL - Encontro de Geógrafos da América Latina, 2013, Lima, Peru. Anais do XIV EGAL - Encontro de Geógrafos da América Latina. Lima, Peru: IGU, 2013. v. 1.

SANTOS, Milton. A Natureza do Espaço: técnica e tempo, razão e emoção. São Paulo: EDUSP, 2002.

SCIFONI, Simone. A construção do patrimônio natural. São Paulo: LABUR, 2008.

SEMUAM, Secretaria Municipal de Meio Ambiente e Urbanismo. Plano de Manejo do Parque Municipal de Nova Iguaçu. Versão Resumida. Nova Iguaçu, 2001.

SENRA, Álvaro de Oliveira. ANDRADE, Flávio Anicio. Uma narrativa alternativa sobre a Baixada Fluminense: a experiência do Jornal da Baixada (1979-1980). Revista Antíteses, v. 10, p. 262-284, 2017.

SILVA, Débora Querino.; SOUSA, Gustavo Mota. Analise exploratória através de estatística espacial: Um estudo de caso na Reserva Biológica do Tinguá. In: XVII Simpósio Brasileiro de Geografia Física Aplicada e I Congresso Nacional de Geografia Física, 2017, Campinas. Os Desafios da Geografia Física na Fronteira do Conhecimento. Campinas: UNICAMP, 2017. v. 1.

TCE/RJ. Tribunal de Contas do Estado do Rio de Janeiro. Estudo Socioeconômico.

TCE/RJ: Rio de Janeiro, 2008. Disponível em: < https://www.tce.rj.gov.br/documents/10180/1092028/Estudo\%20Socioecon\%C3\%B4mico \%202008\%20-\%20Nova\%20Igua\%C3\%A7u.pdf > . Acesso em: Junho de 2020

UNESCO. Convenção para o patrimônio mundial, cultural e natural. Paris. Unesco, 1972. Disponível em: <

http://portal.iphan.gov.br/uploads/ckfinder/arquivos/Recomendacao\%20de\%20Paris\%2019 72.pdf. > Acesso em: Maio de 2020. 